Our study revealed that needles were the major injury-inflicting objects, of which disposable injection syringes accounted for the most. This finding is similar to that of Puro et al. ${ }^{10}$ In terms of work practice, injuries occurred most frequently when the "syringe was recapped with both hands." ${ }^{1,8}$ Since injection syringes were the greatest culprit for needlestick injury from our study, individuals who handle such apparatus should be reminded to be alert and adept in their handling of used needles. Employees also should be encouraged to use appropriate protective measures, such as recapping the syringe single-handedly and using safer products with improved designs. In our hospital, containers that are resistant to puncture were purchased in 1997, so disposable needles can be discarded without recapping. The annual incidence of needle-recapping injury decreased over the period of the study.

Of the incidents reported, 106 involved individuals being cut or slashed by sharp instruments, mostly by suture needles and blades; Jagger et al revealed similar findings. ${ }^{7}$ Our study also revealed a higher incidence of injury when sorting or cleaning medical instruments. Sharp disposable objects should be discarded immediately after use, and they should not be disposed with nonsharp objects.

In addition to the incidence of injury inflicted by sharp-edged medical objects, there were also 24 reports in this present study of the mucosa or broken skin of HCWs being accidentally exposed to blood or body fluids in the work place. In this context, it is suggested that $\mathrm{HCW}_{\mathrm{s}}$ should be advised to observe faithfully all protective measures to avoid direct contact with blood and body fluids in the process of administering medical care to such patients.

This study has also shown that the probability of injury-inflicting objects being contaminated with either blood or body fluid was $94.7 \%$. Due to the high prevalence of HBV carriers in our country, we encourage HCWs to receive $\mathrm{HBV}$ vaccination prior to employment at our hospital. A regular follow-up of sharp-object-injured HCWs by periodic blood testing revealed that one HCW tested positive for $\mathrm{HCV}$ subsequent to a sharp object injury.
In conclusion, a sharp-edged medical-object injury is one of the most frequently seen occupational injuries among HCWs in a hospital work setting. For the sake of safeguarding personal safety and health and avoiding transmission of disease through contact with blood and body fluids, HCWs should heighten their awareness of this type of injury, acquire deft operating skills, and use pertinent protective measures to avoid injury.

From the Section of Infectious Diseases, Department of Medicine, Taipei Veterans General Hospital and National Yang-Ming University of Medicine, Taipei; Nosocomial Infection-Control Committee, Taipei Veterans General Hospital, Taipei, Taiwan, China.

Address reprint requests to Fu-Der Wang, $M D$, Section of Infectious Diseases, Department of Medicine, Taipei Veterans General Hospital, No. 201, Sec. 2, Shih-Pai Rd, Taipei, Taiwan, China.

97-OA-048. Wang F-D, Chen Y-Y, Liu C-Y. Analysis of sharp-edged medical-object injuries at a medical center in Taiwan. Infect Control Hosp Epidemiol 2000;21:656-658.

\section{REFERENCES}

1. APIC position paper: prevention of device-mediated blood-borne infections to health care workers. 1992 Governmental Affairs Committee of the Association for Practitioners in Infection Control, Inc. Am J Infect Control 1993;21:76-78.

2. Haiduven DJ, Phillips ES, Clemons KV, Stevens DA. Percutaneous injury analysis: consistent categorization, effective reduction methods, and future strategies. Infect Control Hosp Epidemiol 1995;16:582-589.

3. Sepkowitz KA. Occupationally acquired infections in health care workers. Part II. Ann Intern Med 1996;125:917-928.

4. Shiao JS, McLaws ML, Huang KY, Ko WC, Guo YL. Prevalence of nonreporting behavior of sharp injuries in Taiwanese health care workers. Am J Infect Control 1999;27:254-257.

5. Mansour AM. Which physicians are at high risk for needlestick injuries? Am J Infect Control 1990;18:208-210.

6. Stotka JL, Wong ES, Williams DS, Stuart CG, Markowitz SM. An analysis of blood and body fluid exposures sustained by house officers, medical students, and nursing personnel on acute-care general medical wards: a prospective study. Infect Control Hosp Epidemiol 1991:12:583-590.

7. Jagger J, Hunt EH, Pearson RD. Sharp object injuries in the hospital: causes and strategies for prevention. Am J Infect Control 1990;18:227-231.

8. White $\mathrm{K}$. "Why weren't you just more careful?" What does it take to avoid occupational exposure to HIV? AIDS Patient Care 1990;6:13-16.

9. Wilkinson WE, Salazar MK, Uhl JE, Koepsell TD, DeRoos RL, Long RJ. Occupational injuries: a study of health care workers at a northwestern health science center and teaching hospital. $A A O H N J$ 1992;40:287-293.

10. Puro V, Petrosillo N, Ippolito G. Risk of hepatitis C seroconversion after occupational exposures in health care workers. Italian Study Group on Occupational Risk of HIV and Other Bloodborne Infections. Am J Infect Control 1995;23:273-277.

\title{
First Responders Not at Occupational Risk of HCV
}

\section{Gina Pugliese, RN, MS Martin S. Favero, PhD}

The CDC recommends that first responders (ie, firefighters, emergency medical technicians, and paramedics) do not need routine testing for hepatitis $\mathrm{C}$ virus $(\mathrm{HCV})$ unless they have a history indicating an increased risk of infection. This recommendation was prompted by inquiries received by the $\mathrm{CDC}$ from state and local health departments and occupational health services about the prevalence of $\mathrm{HCV}$ infection among first responders and the need for routine $\mathrm{HCV}$ testing among these workers. In response, the CDC published a summary of five studies of $\mathrm{HCV}$ infection among first responders. Among the first responders in all five studies, $\mathrm{HCV}$ infection was associated primarily with nonoccupational factors, a finding similar to HBV, a bloodborne virus transmitted at a rate 10 times higher than $\mathrm{HCV}$. Three risk factors accounted for most of the infections: illicit drug use (60\%), highrisk sexual behavior (15\%), and blood transfusion (7\%). These reports indicate that first responders are not at greater risk than the general population for $\mathrm{HCV}$ infection; therefore, routine $\mathrm{HCV}$ testing is not warranted, unless they have a history indicating an increased risk for infection (eg, transfusion before July 1992 or injectingdrug use). It is recommended that first responders should continue to follow Standard Precautions to reduce workplace exposure to bloodborne pathogens.

FROM: Roome AJ, Hadler JL, Thomas AL, Migicovsky B, Roth R, Boraz $M$, et al. Hepatitis $C$ virus infection among firefighters, emergency medical technicians, and paramedics-selected locations, United States, 1991-2000. MMWR 2000;49:660-665. 